\title{
Why Taxing Executives' Bonuses Can Foster Risk-Taking Behavior
}

\author{
Dietl, Helmut ; Grossmann, Martin ; Lang, Markus
}

\begin{abstract}
Bonus taxes have been implemented to prevent managers from taking excessive risks. This paper analyzes the effects of taxing executives' bonuses in a principal-agent model. Our model shows that, contrary to its intention, the introduction of a bonus tax intensifies managers' risk-taking behavior and decreases their effort. The principal responds to a bonus tax by offering the manager a higher fixed salary but a lower incentive-based component (bonus rate).
\end{abstract}

DOI: https://doi.org/10.1628/093245616X14689190842778

Posted at the Zurich Open Repository and Archive, University of Zurich ZORA URL: https://doi.org/10.5167/uzh-132907

Journal Article

Accepted Version

Originally published at:

Dietl, Helmut; Grossmann, Martin; Lang, Markus (2016). Why Taxing Executives' Bonuses Can Foster RiskTaking Behavior. Journal of Institutional and Theoretical Economics, 172(4):645-664.

DOI: https://doi.org/10.1628/093245616X14689190842778 


\title{
Why Taxing Executives' Bonuses Can Foster Risk-Taking Behavior
}

\author{
by \\ Martin Grossmann, Markus Lang, and Helmut Dietl* \\ Received April 2, 2013; in revised form May 8, 2015; \\ accepted December 9, 2015
}

\begin{abstract}
Bonus taxes have been implemented to prevent managers from taking excessive risks. This paper analyzes the effects of taxing executives' bonuses in a principalagent model. Our model shows that, contrary to its intention, the introduction of a bonus tax intensifies managers' risk-taking behavior and decreases their effort. The principal responds to a bonus tax by offering the manager a higher fixed salary but a lower incentive-based component (bonus rate). (JEL: H24, J30, M52)
\end{abstract}

\section{Introduction}

The financial crisis of 2007-2010 was the worst global economic crisis since the Great Depression of the 1930s. Most of the world's largest banks survived only due to unprecedented bailout measures. G" 20 member states contributed US $\$ 7000$ billion to save system-relevant financial institutions and approved economic stimulus packages worth US\$1400 billion in an effort to prevent an ongoing depression. Switzerland, for instance, an important financial center in Europe, was hit hard

\footnotetext{
All the authors are from the Department of Business Administration, University of Zurich, Switzerland. Corresponding author: Markus Lang. Previous versions of this article were presented at the 15th Annual Conference of the International Society for New Institutional Economics (ISNIE) at Stanford University, at the 14th Congress for Personnel Economics at the University of Zurich, and at the 87th Annual Conference of the Western Economic Association in San Francisco. We would like to thank conference participants for helpful comments and suggestions. Martin Grossmann thanks Rakesh Vohra and the Department of Managerial Economics and Decision Sciences at the Northwestern University, Kellogg School of Management for their hospitality during his research stay. Special credit is due to Nenad Kos for helpful comments and suggestions on an earlier draft of this paper. Markus Lang gratefully acknowledges the financial support provided by the Ecoscientia Foundation and the Foundation for the Advancement of Young Scientists (FAN) of the Zürcher Universitätsverein (ZUNIV) as well as the Swiss National Science Foundation (SNSF research project No. 100018-144319).
}

Journal of Institutional and Theoretical Economics 172, 1-20 - ISSN 0932-4569 DOI: 10.1628/093245616X14689190842778 - (C) 2016 Mohr Siebeck 
(Buehler, Kaiser, and Jaeger, 2012). Its flagship bank, UBS, threatened to drag the entire economy into turmoil.

The excessive risk-taking of corporate executives is commonly considered to be one important cause of this crisis. It is well known that one reason for excessive risk-taking can be found in the limited liability of corporate executives (e.g., Thanassoulis, 2009; Bebchuk and Spamann, 2010). Bank executives' pay has been tied to highly leveraged bets on the value of bank assets. Due to their limited liability, executives benefit from the upside and are protected from the downside. As a result, executives have little incentive to take into account the losses that risk-taking could impose on shareholders and taxpayers.

As a response to the crisis, bonus taxes have been implemented in several countries. For example, in 2009 the U.S. House of Representatives approved a $90 \%$ tax on bonuses in firms that have received federal bailout money. In a similar fashion, Ireland introduced a $90 \%$ tax on executives' bonuses in January 2011. In the UK, bankers' bonuses were taxed at $50 \%$ for a period of several months in 2010 .

Proponents of bonus taxes or pay caps for executives argue that these instruments will prevent greedy managers from excessive risk-taking by limiting the upside potential of any form of risk-taking. On June 30, 2010, Arlene McCarthy, the rapporteur in charge of the negotiations for the European Parliament, said in reaction to the implemented cap on bankers' bonuses: "Two years on from the global financial crisis, these tough new rules on bonuses will transform the bonus culture and end incentives for excessive risk-taking. A high-risk and short-term bonus culture wrought havoc with the global economy and taxpayers paid the price. The public want banks to prioritize stability and lending over their own pay and perks. In the last two years the banks have failed to reform, and we are now doing the job for them."

This paper analyzes the effect of a bonus tax on the manager's risk-taking behavior in a principal-agent model. Basic intuition might suggest that when the bonus is taxed, the manager will react with lower risk-taking. Yet, the opposite is true. Our model shows that, contrary to its intention, a bonus tax increases the manager's risk-taking behavior and decreases the manager's effort. Furthermore, we derive that the manager's fixed salary increases, while the incentive-based salary component (bonus rate) decreases. It is important to note that the objective of this paper is not to analyze the interaction between limited liability and bonus taxes, but to isolate the incentive effects of bonus taxes.

Before we proceed with the model, we will give a brief overview of the related literature. The principal-agent problem arises through asymmetric information and diverging interests between ownership and control. This agency problem was first formalized by Jensen and Meckling (1976) and subsequently extended in various directions (Mirrlees, 1976; Holmström, 1979; Holmstrom, 1982; Fama, 1980; Lazear and Rosen, 1981; Grossman and Hart, 1983). The evolving literature on

1 See "European Parliament caps bankers' bonuses," European Parliament, June, 30th, 2010 (www.europarl.europa.eu/news/en/news-room/20100630IPR77285). 
executive compensation has been highly interdisciplinary and has spanned finance, accounting, economics, industrial relations, strategy, organizational behavior, and law. ${ }^{2}$

Even though there is a huge body of literature and numerous theoretical and empirical research on executive pay, only a few papers study the consequences of executive pay regulation. For instance, Dew-Becker (2009) analyzes the government regulation of executive compensation in the U.S. By discussing disclosure rules, advancements in corporate governance, and say-on-pay, he analyzes the evolution of pay regulation and concludes that mandatory say-on-pay could be the most effective and least harmful measure of controlling executive compensation. Knutt (2005) examines diverse regulatory issues from a legal point of view. In this study, he proposes the installation of independent compensation committees to support current regulation practices. Hall and Liebman (2000) analyzes the extent to which tax policy influences the composition of executive compensation and discusses the consequences of rising stock-based pay.

However, to the best of our knowledge the effects of bonus taxes on executives' risk-taking have not yet been analyzed in the agency literature. ${ }^{3}$ Dietl et al. (2013) analyze the incentive effects of bonus taxes. They find that the effect of a bonus tax on the agent's compensation components depends on the interaction of the agent's level of risk aversion and the variance in the firm value. In contrast to our article, they do not study how a bonus tax affects the risk-taking behavior of the agent. Our model is also related to Holmstrom and Milgrom (1987) and Hirshleifer and Suh (1992) in the following dimensions. We base our principal-agent model on Holmstrom and Milgrom (1987) and introduce a tax that is levied on the agent's bonus. To model the firm value, we follow the approach of Hirshleifer and Suh (1992) and assume additive separability between effort and risk in the output function.

The remainder of the paper is structured as follows. In section 2, we develop our principal-agent model. Section 3 analyzes the problem of the agent and the principal, respectively. Furthermore, the optimality conditions are derived and discussed. In section 4, we present our results for a specific effort cost function. In section 5 , we examine the sensitivity of our results to alternative specifications. Section 6 summarizes the main results and concludes the paper.

\footnotetext{
${ }^{2}$ For comprehensive surveys of research on executive compensation, see, e.g., GomezMejia, McCann, and Page (1985); Murphy (1999); Core, Guay, and Larcker (2003); and Devers et al. (2007).

3 A strand of literature exists that analyzes the relation between stock-option-based executive compensation and risk-taking. For example, based on 591 bank-CEO-year observations from 1992 to 2000, Chen, Steiner, and Whyte (2006) find that the stock of option-based wealth leads to higher risk-taking in the banking industry. For theoretical models that analyze the incentive effects of executive stock options, see Carmel (2008) and Garvey, Grant, and King (1999).
} 


\section{Model Setup}

We consider a single-period employment relationship in a firm between a riskneutral principal and a risk-averse agent. The agent has two unobservable choice variables to influence the firm value (output) denoted by $x$ : productive effort $a \in \mathbb{R}^{+}$ and risk-taking behavior $b \in \mathbb{R}^{+}$. To model the firm value, we follow Hirshleifer and Suh (1992) and assume that

$$
x=a+b(k+\varepsilon),
$$

where $\varepsilon \sim N\left(0, \sigma_{\varepsilon}^{2}\right)$ and $k \in \mathbb{R}^{+}$. The parameter $b$ can be interpreted as the agent's choice of operating risky projects where the project return is captured by the parameter $k$. Hence, the agent can influence the firm value by exerting a certain effort $a$ or by choosing a certain risk $b$. The agent's risk choice $b$ has two effects: on the one hand, given $k>0$, a riskier behavior increases the expected firm value $E[x]=a+k b$, but on the other hand, it also increases the variance in the firm value, $V[x]=b^{2} \sigma_{\varepsilon}^{2}$. A higher value of the error term $\sigma_{\varepsilon}^{2}$ can be interpreted as a more uncertain economic environment (Bustamante, 2014) that creates a high variance in the firm value or, alternatively, a situation in which the agent's performance cannot be measured precisely.

We follow Hirshleifer and Suh (1992) with respect to the following two points. First, we assume that only effort $a$ is costly, where $c(a) \in C^{2}$ with $c^{\prime}(a)>0$, $c^{\prime \prime}(a)>0$ for $a>0, c^{\prime}(0)=0, c^{\prime \prime}(0)=0$. Second, we neglect the agent's limited liability. ${ }^{4}$ Our objective is to analyze the incentive effects of bonus taxes in isolation and not the interaction with limited liability. We know already from the literature that limited liability increases the incentives for risk-taking (Thanassoulis, 2009, and Bebchuk and Spamann, 2010).

Following the classic models in agency theory (Gibbons, 1998), the agent's salary $p(x)$ is linear and has two components: a fixed component and an incentivebased component. We denote the fixed component by $\delta \in \mathbb{R}^{+}$and refer to it as the fixed salary. We refer to the incentive-based component $\gamma x$ as the bonus, with $\gamma$ being the bonus rate (Gibbons, 1998, p. 116). ${ }^{5}$ The bonus is taxed at $\tau \in(0,1)$, so that the agent's (net-of-tax) salary becomes ${ }^{6}$

$$
p(x)=\delta+(1-\tau) \gamma x .
$$

${ }^{4}$ For a paper that integrates limited liability in a principal-agent model, see, e.g., Sherstyuk (2000), who discusses how punishment threats in contracts can discipline agents.

5 Note that in the literature on executive compensation $\gamma$ is also referred to as the payperformance sensitivity (PPS) or piece rate (see, e.g., Jensen and Murphy, 1990; Murphy, 1999; Faulkender et al., 2010; Schöttner and Thiele, 2010; Agranov and Tergiman, 2013).

6 In line with the agency literature, we assume that the principal offers the agent a linear employment contract (see, e.g., Feltham and Xie, 1994; Baker, 2002; Wernerfelt, 2004; Hughes, Zhang, and Xie, 2005). In addition, for certain intertemporal contracting problems in discrete and continuous time, it can be shown that the optimal dynamic compensation scheme is linear (Holmstrom and Milgrom, 1987; Hellwig and Schmidt, 2002). 
Because $\varepsilon$ is normally distributed and it is the only random variable in $p(x)$, it follows that $p(x)$ is normally distributed, too:

$$
p(x) \sim N\left(\delta+(1-\tau) \gamma(a+k b) ; b^{2}(1-\tau)^{2} \gamma^{2} \sigma_{\varepsilon}^{2}\right) .
$$

The agent has an expected salary of $E[p]=\delta+(1-\tau) \gamma(a+k b)$ with a variance given by $V[p]=b^{2}(1-\tau)^{2} \gamma^{2} \sigma_{\varepsilon}^{2}$. Hence, the gross salary paid by the principal is $\delta+\gamma x$, while the agent receives only a net-of-tax salary of $\delta+(1-\tau) \gamma x$. The government gains $\tau \gamma x$ as tax revenues. Because our paper focuses on bonus taxes, we do not consider other taxes such as income taxes on the agent's salary or corporate income taxes. $^{7}$

The agent is assumed to be risk-averse with a constant absolute risk-averse (CARA) utility function $U(p, a)=-e^{-r(p-c(a))}$, where $r \in \mathbb{R}^{+}$is the agent's level of absolute risk aversion. The agent's expected net utility $E\left[U_{A}\right]$ can then be derived as (see, e.g., Conyon and Sadler, 2001)

$$
E\left[U_{A}\right]=\delta+(1-\tau) \gamma(a+k b)-\frac{1}{2} r \sigma_{\varepsilon}^{2} b^{2}(1-\tau)^{2} \gamma^{2}-c(a),
$$

where $(1 / 2) r \sigma_{\varepsilon}^{2} b^{2}(1-\tau)^{2} \gamma^{2}$ is the agent's risk premium required to compensate him for the uncertainty in his expected salary. Moreover, the agent has an exogenous outside option $\omega \in \mathbb{R}^{+}$. The outside option can be interpreted as the utility the agent would receive in another firm or in a country without a bonus tax and therefore is assumed to be exogenous. ${ }^{8}$

The risk-neutral principal maximizes her expected profit $E\left[\pi_{P}\right]$, which is given by the expected output $E[x]$ minus the expected gross salary payment $E[\delta+\gamma x]$ :

$$
E\left[\pi_{P}\right]=(1-\gamma)(a+k b)-\delta .
$$

The timing has the following structure. First, the principal offers the agent the employment contract $(\delta, \gamma)$ given the bonus tax $\tau \in(0,1)$ set by the state. Second, the agent either accepts the principal's offer or chooses the outside option $\omega$. After accepting the contract, the agent elicits effort $a$ and risk-taking $b$.

\section{Analysis}

\subsection{The Agent's Problem}

For a given compensation package $(\delta, \gamma)$ provided by the principal, the agent maximizes his expected net utility $E\left[U_{A}\right]$ with respect to $(a, b)$. Henceforth, we denote by $\rho$ the product of the agent's level of risk aversion $r$ and the variance in the firm

\footnotetext{
7 For a study that analyzes different principals for the taxation of multinational enterprises, see e.g., Eichner and Runkel (2011).

8 In section 5, we analyze the implications of an endogenously determined outside option.
} 
value $\sigma_{\varepsilon}^{2}$, i.e., $\rho \equiv r \sigma_{\varepsilon}^{2}$. We refer to $\rho$ as the risk parameter. The agent's maximization problem is then formally given by

$$
\max _{(a, b) \geq 0}\left\{E\left[U_{A}\right]=\delta+(1-\tau) \gamma(a+k b)-b^{2} \frac{\rho}{2}(1-\tau)^{2} \gamma^{2}-c(a)\right\}
$$

with the corresponding first-order conditions: ${ }^{9}$

(1) $\frac{\partial E\left[U_{A}\right]}{\partial a}=(1-\tau) \gamma-c^{\prime}\left(a^{*}\right)=0$ and $\frac{\partial E\left[U_{A}\right]}{\partial b}=(1-\tau) \gamma k-\rho b^{*}(1-\tau)^{2} \gamma^{2}=0$.

A higher effort $a$ and a riskier behavior $b$ generate marginal benefits $(1-\tau) \gamma$ and $(1-\tau) \gamma k$, respectively, due to the higher expected firm value. At the same time, they induce marginal costs of $c^{\prime}\left(a^{*}\right)$ and $\rho b^{*}(1-\tau)^{2} \gamma^{2}$ due to larger effort costs and a larger variance in the firm value, respectively. The first-order conditions state that, in equilibrium, the marginal benefits of a higher effort and a riskier behavior must be equal to the corresponding marginal costs. Based on the first-order conditions, we establish the following lemma:

LEMMA 1 A higher bonus rate $\gamma$ increases the effort $a^{*}$ and reduces the risk-taking $b^{*}$ of the agent.

PROoF Straightforward and therefore omitted.

A higher bonus rate increases the agent's effort because the marginal revenue of effort increases; at the same time, a higher bonus rate increases the marginal revenue of risk-taking, $(1-\tau) \gamma k$. However, the marginal cost of risk-taking, $b^{*} \rho(1-\tau)^{2} \gamma^{2}$, also increases for a higher bonus rate, due to a higher net-of-tax variance in the salary. Because the latter (negative) effect dominates the former (positive) effect, the agent reduces risk-taking.

\subsection{The Principal's Problem}

The principal maximizes her expected profit $E\left[\pi_{P}\right]$ by choosing an optimal compensation package $\left(\gamma^{*}, \delta^{*}\right)$ and by taking into account the optimal behavior of the agent. Formally, the principal solves the following maximization problem: ${ }^{10}$

$$
\max _{(\delta, \gamma) \geq 0}\left\{E\left[\pi_{P}\right]=(1-\gamma)(a+k b)-\delta\right\},
$$

subject to the participation constraint (PC)

$$
E\left[U_{A}\right]=\delta+(1-\tau) \gamma\left(a^{*}+k b^{*}\right)-\left(b^{*}\right)^{2} \frac{\rho}{2}(1-\tau)^{2} \gamma^{2}-c\left(a^{*}\right) \geq \omega
$$

\footnotetext{
9 It is easy to verify that the second-order conditions for the maximum are satisfied.

10 We implicitly assume that, e.g., the outside option $\omega$ and the bonus tax $\tau$ are sufficiently small so that the principal obtains nonnegative equilibrium profits.
} 
and the incentive compatibility constraint (ICC)

$$
\left(a^{*}, b^{*}\right) \in \underset{(a, b) \geq 0}{\arg \max } E\left[U_{A}\right] .
$$

We derive the corresponding first-order condition in the following lemma. ${ }^{11}$

LEMma 2 The first-order condition of the principal is given by

$$
\underbrace{1-\frac{k^{2} c^{\prime \prime}\left(a^{*}\right)}{\rho c^{\prime}\left(a^{*}\right)^{2}}}_{\text {revenue effect }}=\underbrace{\gamma+\frac{\tau}{1-\tau} c^{\prime \prime}\left(a^{*}\right) a^{*}}_{\text {cost effect }} .
$$

Marginally increasing the bonus rate induces a marginal increase in the agent's effort, which has the following effects for the principal. On the one hand, an increase in the agent's effort generates a revenue effect (left-hand side): a one-unit increase in the agent's effort implies one-to-one higher expected revenue for the principal (first term), but at the same time a higher level of effort negatively affects the agent's risk-taking, which reduces the marginal revenue (second term). On the other hand, an increase in the agent's effort generates a cost effect (right-hand side) because the principal incurs the full cost of the bonus, while the agent receives only a fraction $1-\tau$ of it. This effect, which makes the use of a bonus more costly for the principal, reflects the "leakage" in the contracting environment stemming from the bonus tax. The cost effect is composed of two parts. (i) Higher effort generates higher costs for the principal, $\gamma+c^{\prime \prime}\left(a^{*}\right) a^{*} /(1-\tau)$, because she must pay the agent a higher bonus and incurs the full cost of the bonus. (ii) Higher effort generates also more income for the agent, which relaxes the PC, and hence attenuates the cost effect. This income effect is given by $-c^{\prime \prime}\left(a^{*}\right) a^{*}$. Combining (i) and (ii) produces the cost effect.

\subsection{Equilibrium}

In equilibrium, the principal offers the compensation package $\left(\gamma^{*}, \delta^{*}\right)$, and the agent responds with effort $a^{*}$ and risk-taking $b^{*}$, which are implicitly defined by

$$
\begin{gathered}
\gamma^{*}=1-c^{\prime \prime}\left(a^{*}\right)\left(\frac{k^{2}}{\rho\left(\gamma^{*}\right)^{2}(1-\tau)^{2}}+a^{*} \frac{\tau}{1-\tau}\right), \delta^{*}=\omega-(1-\tau) \gamma^{*} a^{*}-\frac{k^{2}}{2 \rho}+c\left(a^{*}\right), \\
c^{\prime}\left(a^{*}\right)=(1-\tau) \gamma^{*}, b^{*}=\frac{k}{\rho(1-\tau) \gamma^{*}} .
\end{gathered}
$$

The two equations in (4) represent the agent's optimal behavior, and the equations in (3) are derived by simplifying the principal's first-order condition and the $\mathrm{PC}$, respectively.

\footnotetext{
11 All proofs can be found in the appendix.
} 


\section{Results}

To derive further insights, we specify the effort cost function and assume quadratic effort costs, i.e., $c(a)=(1 / 2) a^{2}$. This assumption is common in the corresponding principal-agent literature (see, e.g., Schaefer, 1998; Baker, 2002; Laux and Laux, 2006; Marino and Zábojník, 2008; Roider, 2009). We proceed as follows. First, we show the conditions under which an equilibrium exists and is unique. Second, we analyze the effects of a bonus tax on the principal's and the agent's behavior. Third, we analyze the effect of the risk and project return parameters on the principal's and the agent's behavior.

For a quadratic effort cost function, the equations (4) and (3) simplify to

$$
\begin{aligned}
& \left(\gamma^{*}, \delta^{*}\right)=\left(1-\frac{k^{2}}{\rho\left(a^{*}\right)^{2}}-a^{*} \frac{\tau}{1-\tau}, \omega-\frac{1}{2}(1-\tau)^{2}\left(\gamma^{*}\right)^{2}-\frac{k^{2}}{2 \rho}\right), \\
& \left(a^{*}, b^{*}\right)=\left((1-\tau) \gamma^{*}, \frac{k}{\rho(1-\tau) \gamma^{*}}\right) .
\end{aligned}
$$

It should be noted that the equilibrium $\left(\gamma^{*}, \delta^{*}, a^{*}, b^{*}\right)$ is still defined only implicitly. We establish the following lemma, which holds for quadratic effort cost functions.

LemMa 3 For quadratic effort costs, a unique equilibrium exists if and only if $k^{2}<$ $k_{\max } \equiv(4 / 27) \rho(1-\tau)^{2} /(1+\tau)^{2}$.

It follows from Lemma 3 that the project return parameter $k$ must satisfy an upper bound defined by $k^{2}<k_{\max }$ to ensure the existence of a unique maximum. The reason for this bound is as follows. A higher $k$ increases the marginal revenue of risk-taking, so that $b$ increases. A higher $b$, in turn, decreases the effort $a$ according to Lemma 1. The lower effort $a$ then decreases the bonus rate $\gamma$ (see (1)), which yields a lower variance in the agent's salary. As a result, the "cost" of risk-taking decreases and converges to zero as the bonus rate converges to zero. The agent would now have incentives to choose an infinitely high level of risk-taking behavior $b$. Therefore, an upper bound must be imposed on the project return parameter $k$. In the subsequent analysis, we assume that $k^{2}<k_{\max }$ to ensure the existence of a unique equilibrium $\gamma^{*}$.

In a next step, we analyze the effects of a higher bonus tax on the compensation package $\left(\gamma^{*}, \delta^{*}\right)$ and the agent's behavior $\left(a^{*}, b^{*}\right)$. We establish the following proposition, which summarizes our results.

Proposition 1 Under the assumption of quadratic effort costs, a higher bonus tax $\tau$ has the following effects in equilibrium:

(i) The principal reduces the bonus rate and increases the fixed salary $\left(\partial \gamma^{*} / \partial \tau<0\right.$ and $\left.\partial \delta^{*} / \partial \tau>0\right)$.

(ii) The agent reduces effort and increases risk-taking behavior $\left(\partial a^{*} / \partial \tau<0\right.$ and $\left.\partial b^{*} / \partial \tau>0\right)$.

Part (i) shows that a bonus tax leads to a lower bonus rate and a higher fixed salary, yielding therefore a lower incentive power of the contract. The result with 
respect to the bonus rate is intuitive from observing the principal's first-order condition given by (2). A higher tax has no direct effect on the revenue effect, but it strengthens the cost effect because the agent receives a lower fraction of the bonus paid by the principal. As a result, the principal lowers $\gamma$ if the bonus tax increases. Furthermore, the principal chooses the fixed salary so that the PC is satisfied. On the one hand, a higher bonus tax induces a lower bonus, but on the other hand, it also lowers costs for the agent because his effort decreases. In equilibrium, the decrease in the bonus is stronger than the decrease in the agent's costs, so that the fixed salary must increase to satisfy the PC. Therefore, the introduction of a bonus tax shifts the compensation package from the incentive-based component (bonus rate) to the fixed salary.

Part (ii) shows that, contrary to its intention, a bonus tax induces the agent to decrease effort and to increase risk-taking. By observing the agent's first-order conditions given by (1), we derive the intuition for this result as follows. Recall that the marginal benefits of effort and risk-taking are given by $(1-\tau) \gamma$ and $(1-\tau) \gamma k$, respectively. A higher bonus tax has a direct negative effect on these marginal benefits, because it decreases the fraction $1-\tau$ that the agent receives from the bonus. Moreover, a higher tax induces the principal to decrease the bonus rate $\gamma^{*}$ in equilibrium, yielding an indirect negative effect on the agent's marginal benefits. As a result, the agent decreases $a^{*}$ in equilibrium, because the tax has no (direct) effect on the marginal effort costs $c^{\prime}(a)$. However, a higher tax has a positive effect on the marginal costs $b \rho(1-\tau)^{2} \gamma^{2}$ of risk-taking because it decreases the salary variance. The positive effect dominates the negative effect, and as a result the agent chooses a riskier behavior $b^{*}$ in equilibrium.

So far, we have analyzed the effect of a bonus tax. It is also interesting to consider the effect of the risk parameter as well as the project return parameter. The following proposition sheds light on this issue.

PRoposition 2 Assuming quadratic effort costs, we derive the following results:

(i) A higher risk parameter induces the principal to increase the bonus rate $\left(\partial \gamma^{*} / \partial \rho>0\right)$, while the agent reacts with higher effort and lower risk-taking behavior $\left(\partial a^{*} / \partial \rho>0\right.$ and $\left.\partial b^{*} / \partial \rho<0\right)$.

(ii) A higher project return parameter induces the principal to reduce the bonus rate $\left(\partial \gamma^{*} / \partial k<0\right)$, while the agent reacts with lower effort and higher risk-taking behavior $\left(\partial a^{*} / \partial k<0\right.$ and $\left.\partial b^{*} / \partial k>0\right)$.

Part (i) of the proposition shows that the compensation package shifts to the incentive-based component if the agent is more risk-averse and/or the uncertainty in the economic environment increases. ${ }^{12}$ In addition, the agent reduces risk-taking and increases effort. Because a higher risk parameter only increases the revenue effect and does not influence the cost effect in the principal's first-order condition (2),

\footnotetext{
12 Recall that a higher risk parameter $\rho$ is the result of a higher risk aversion $r$ of the agent and/or a higher level of uncertainty in the economic environment reflected by a higher variance $\sigma_{\varepsilon}^{2}$.
} 
the principal increases the bonus rate. It is intuitive that a higher risk parameter induces the agent to decrease his risk-taking behavior due to the increase in his risk premium. As a consequence, the agent increases his effort according to Lemma 1.

Regarding part (ii) of the proposition, it is intuitive that the principal lowers the bonus rate for a higher risk parameter because a higher $k$ decreases the revenue effect but has no impact on the cost effect in the principal's first-order condition (2). The agent reduces effort and increases risk-taking for a higher project return parameter because, according to the agent's first-order condition (1), a higher $k$ has a direct positive impact on the marginal benefits but no direct impact on the marginal costs of a riskier behavior.

Depending on the industry and the resulting degree of risk aversion, the level of uncertainty in the economic environment, and the size of the project return parameter, a principal should take into account the relationships derived in Proposition 2 when hiring a new agent.

\section{Robustness}

In this section, we show that our results are robust with respect to the exogeneity of the outside option and the specification of the cost function. First, we examine the effects of relaxing the assumption regarding the exogenous outside option. Second, we numerically simulate the model for effort cost functions with a constant cost elasticity.

Endogenous Outside Option. So far, we have assumed that the agent's outside option $\omega$ is exogenously given. Recall that the agent always has the possibility to leave the country that has introduced a bonus tax. However, one could argue that the agent's value of his outside option decreases with a higher bonus tax because (i) finding new employment in another country generates costs for the agent and/or (ii) the value of the (new) outside option decreases if the agent changes his job. In the case of an endogenously given outside option $\omega(\tau)$, we establish the following corollary.

Corollary Suppose that the outside option $\omega(\tau)$ depends negatively on the tax rate, i.e., $\partial \omega(\tau) / \partial \tau<0$. In this case, the results of Proposition 1 remain unchanged except for the effect of a bonus tax on the fixed salary $\delta^{*}$. If $|\partial \omega(\tau) / \partial \tau|>$ $a^{*}\left|\partial a^{*} / \partial \tau\right|$, then a higher bonus tax also induces a decrease in the fixed salary, i.e., $\partial \delta^{*} / \partial \tau<0$.

Proof The proof is straightforward, by noting that $\delta^{*}=\omega(\tau)-(1 / 2)\left(a^{*}\right)^{2}+$ $3 k^{2} /(2 \rho)$ and $\partial \delta^{*} / \partial \tau=\partial \omega(\tau) / \partial \tau-a^{*}\left(\partial a^{*} / \partial \tau\right)$. Hence, $\partial \delta^{*} / \partial \tau<0 \Leftrightarrow$ $|\partial \omega(\tau) / \partial \tau|>a^{*}\left|\partial a^{*} / \partial \tau\right|$.

The result of the corollary is intuitive. We know that in the case of an exogenous outside option, a higher bonus tax induces a shift in the compensation package 
Figure 1

Bonus Tax Effects for Different Polynomial Cost Functions

(a) Tax Effect on Effort

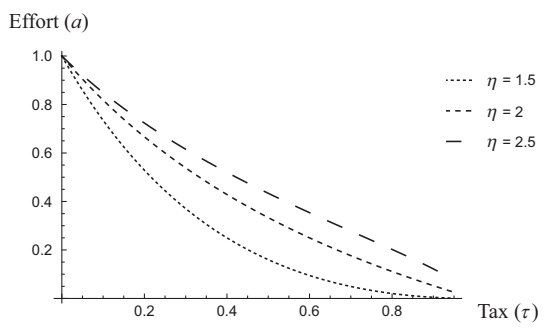

(c) Tax Effect on Bonus Rate

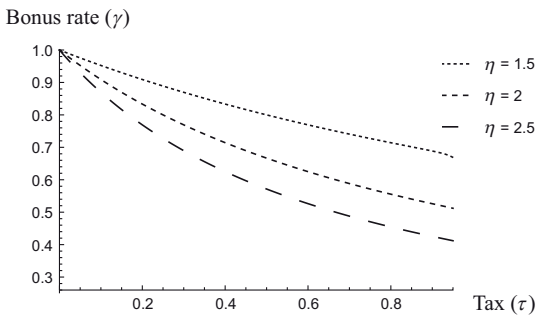

(b) Tax Effect on Risk-Taking

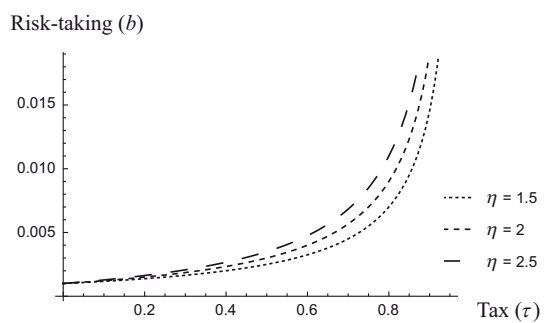

(d) Tax Effect on Fixed Salary

Fixed salary $(\delta)$

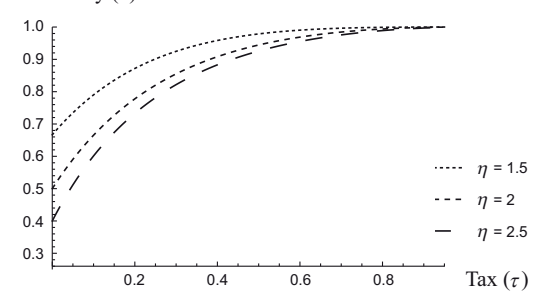

from the incentive-based component (bonus rate) to the fixed salary. If, however, the outside option depends on the bonus tax and a higher tax induces a sufficiently strong decrease in the value of the outside option, i.e., $|\partial \omega(\tau) / \partial \tau|>a^{*}\left|\partial a^{*} / \partial \tau\right|$, then the principal can decrease both the bonus rate and the fixed salary and still satisfy the agent's PC.

Effort Cost Function. To verify the robustness of our model regarding the specification of the cost function, we analyze the solutions to the equations (3) and (4) for polynomial cost functions $c(a)=a^{\eta} / \eta$ with $\eta=[1.5,2.5]$. Because the solutions to the model are only implicit, we need to run a simulation. We set the parameters as follows: $\omega=1, \rho=1, \tau \in[0 ; 0.95]$, and $k=0.001$. Figure 1 illustrates the results for $\eta \in\{1.5,2,2.5\}$ and displays the effect of the bonus tax $\tau$ on the agent's effort and risk-taking, and on the principal's choice of the bonus rate and the fixed salary. We find that qualitatively, the results from Proposition 1 derived for the quadratic cost function with $\eta=2$ also hold for other polynomial cost functions with $\eta$ close to $2 .{ }^{13}$

\footnotetext{
13 We also tested other values of $\eta$ in the interval $\eta=[1.5,2.5]$ and find robust results.
} 


\section{Conclusion}

This paper has analyzed the effect of a bonus tax on the risk-taking behavior of corporate executives in a principal-agent model. In our paper, the firm value (output) depends on the manager's behavior in two dimensions. First, the manager can influence the firm value by exerting a certain effort. Second, the manager can choose a project with specific exposure. A project choice with a higher expected return simultaneously implies a higher risk. Therefore, the project choice influences the expected value as well as the variance in the output. For instance, bank managers dealing with credits face this kind of trade-off. Credit at low interest rates can be assigned to firms with high ratings. Therefore, the bank has low expected profits but also low risks. Otherwise, credit at higher interest rates can be assigned to a start-up firm operating in a promising area but with high uncertainty. Thus, a higher expected return can be achieved by being exposed to higher risks. We assume that the principal offers a salary package consisting of a fixed salary and an incentivebased component (bonus rate). The bonus rate increases with the manager's output. As the manager can only influence the output by his effort choice and the degree of exposure, the realization or failure of the project is stochastic.

Our model shows that the introduction of a bonus tax unintentionally intensifies the manager's risk-taking behavior and decreases the manager's effort. On the one hand, a higher tax decreases the marginal revenue of risky projects, but on the other hand, it also decreases the variance in the manager's salary, implying lower marginal costs. The second effect dominates the first, and therefore a higher bonus tax induces the manager to increase his risk-taking behavior. Simultaneously, the manager decreases his effort because a higher bonus tax decreases the marginal revenue of effort. We further show that a higher bonus tax shifts the compensation package from the incentive-based component to the fixed salary. Finally, a higher risk aversion of the manager and/or a higher variance in the firm value induces the manager to increase his effort and to decrease his risk-taking behavior, while the principal increases the bonus rate.

Our results imply that a government should be careful when evaluating whether a bonus tax is an appropriate instrument to introduce in order to prevent the excessive risk-taking behavior of corporate executives. This article is a first step in analyzing the effects of a bonus tax on risk-taking behavior in a principal-agent model. An interesting avenue for further research would be to formally analyze the interaction between limited liability and a bonus tax.

In our opinion, the issues surrounding the implications of bonus taxes remain a fertile and important line of inquiry for economists, politicians, and regulators. 
Appendix

\section{A.1 Proof of Lemma 2}

With PC, the expected profit of the principal is given by

$$
E\left[\pi_{P}\right]=(1-\gamma)(a+k b)-\omega+(1-\tau) \gamma(a+k b)-b^{2} \frac{\rho}{2}(1-\tau)^{2} \gamma^{2}-c(a) .
$$

Together with ICC, $\gamma=c^{\prime}(a) /(1-\tau)$ and $b=k /\left(\rho c^{\prime}(a)\right)$, we obtain

$$
E\left[\pi_{P}\right]=\left(1-\frac{c^{\prime}(a)}{1-\tau}\right)\left[a+\frac{k^{2}}{\rho c^{\prime}(a)}\right]-\omega+c^{\prime}(a)\left[a+\frac{k^{2}}{\rho c^{\prime}(a)}\right]-\frac{k^{2}}{2 \rho}-c(a) .
$$

Due to the relation $\gamma=c^{\prime}(a) /(1-\tau)$ between the effort $a$ and the bonus rate $\gamma$ given by the ICC, the principal is able to control the effort $a$. Therefore, we derive the first-order condition of the principal as

$$
\begin{aligned}
\frac{\partial E\left[\pi_{P}\right]}{\partial a}= & \left(1-\frac{c^{\prime}(a)}{1-\tau}\right)\left[1-\frac{k^{2} c^{\prime \prime}(a)}{\rho c^{\prime}(a)^{2}}\right]-\frac{c^{\prime \prime}(a)}{1-\tau}\left[a+\frac{k^{2}}{\rho c^{\prime}(a)}\right] \\
& +c^{\prime \prime}(a)\left[a+\frac{k^{2}}{\rho c^{\prime}(a)}\right]+c^{\prime}(a)\left[1-\frac{k^{2} c^{\prime \prime}(a)}{\rho c^{\prime}(a)^{2}}\right]-c^{\prime}(a)=0 .
\end{aligned}
$$

Resubstitution of $c^{\prime}(a)=(1-\tau) \gamma$ yields the first-order condition of the principal as

$$
\begin{aligned}
& (1-\gamma)\left[1-\frac{k^{2} c^{\prime \prime}(a)}{\rho(1-\tau)^{2} \gamma^{2}}\right]-\frac{c^{\prime \prime}(a)}{1-\tau}\left[a+\frac{k^{2}}{\rho(1-\tau) \gamma}\right] \\
& \quad+c^{\prime \prime}(a)\left[a+\frac{k^{2}}{\rho(1-\tau) \gamma}\right]+(1-\tau) \gamma\left[1-\frac{k^{2} c^{\prime \prime}(a)}{\rho(1-\tau)^{2} \gamma^{2}}\right]-(1-\tau) \gamma=0 .
\end{aligned}
$$

Rearranging of the first-order condition produces the claim.

Q.E.D.

\section{A.2 Proof of Lemma 3}

Step 1: The principal's first-order condition, $\gamma^{*}=1-k^{2} /\left(\rho\left(a^{*}\right)^{2}\right)-a^{*} \tau /(1-\tau)$, can also be written as

(A1) $F(\gamma) \equiv(1-\tau)-\gamma\left(1-\tau^{2}\right)-\frac{k^{2}}{\rho \gamma^{2}(1-\tau)}=\frac{\rho \gamma^{2}(1-\tau)^{2}[1-\gamma(1+\tau)]-k^{2}}{\rho \gamma^{2}(1-\tau)}=0$,

taking into account that $a=(1-\tau) \gamma$. We illustrate equation (A1) as a function of $\gamma$ in Figure A1 for $k=0.005, \tau=0.3$, and $\rho=1$.

The principal's second-order condition is given by

$$
\frac{\partial F(\gamma)}{\partial \gamma}=\frac{2 k^{2}}{\rho \gamma^{3}(1-\tau)}-\left(1-\tau^{2}\right) \stackrel{\gamma=a /(1-\tau)}{=}(1-\tau)\left[\frac{2 k^{2}(1-\tau)}{\rho a^{3}}-(1+\tau)\right] .
$$

Hence, the SOC is satisfied if and only if

$$
k^{2}<k_{\mathrm{SOC}} \equiv \frac{\rho(1+\tau)}{2(1-\tau)} a^{3} \stackrel{a=(1-\tau) \gamma}{=} \frac{1}{2} \rho \gamma^{3}(1-\tau)^{2}(1+\tau) .
$$


Figure Al

The First-Order Condition of the Principal

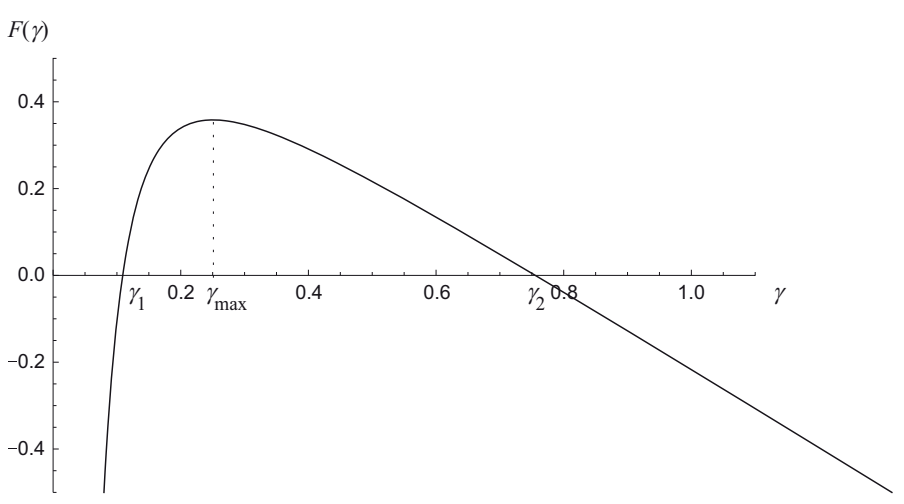

Step 2: We derive the following properties of the principal's first-order condition $F(\gamma)=0$ :

1. $F(\gamma)$ is a continuous function in $\gamma \in(0,1)$.

2. $\lim _{\gamma \rightarrow 0} F(\gamma)=-\infty$ and $F(1)=-\tau(1-\tau)-k^{2} /(\rho(1-\tau))<0$.

3. $\partial F(\gamma) / \partial \gamma=-\left(1-\tau^{2}\right)+2 k^{2} /\left(\rho \gamma^{3}(1-\tau)\right)=0 \Leftrightarrow \gamma=\gamma_{\max } \equiv\left(2 k^{2} /\left(\rho(1-\tau)^{2}(1+\right.\right.$ $\tau)))^{1 / 3}$. We further derive $F\left(\gamma_{\max }\right)>0 \Leftrightarrow k^{2}<k_{\max } \equiv(4 / 27) \rho(1-\tau)^{2} /(1+\tau)^{2}$ and $\gamma_{\max } \in(0,1)$ for $k^{2}<k_{\max } \cdot{ }^{14}$

4. $\gamma_{\max }$ is a local maximum of $F(\gamma)$, because $\partial^{2} F(\gamma) / \partial \gamma^{2}=-6 k^{2} /\left(\rho \gamma^{4}(1-\tau)\right)<0$. Hence, $\partial F(\gamma) / \partial \gamma>0$ for $\gamma<\gamma_{\max }$, and $\partial F(\gamma) / \partial \gamma<0$ for $\gamma>\gamma_{\max }$.

From properties 1-4, we derive that for $k^{2}<k_{\max }$ the first-order condition $F(\gamma)=0$ has exactly two roots $\left(\gamma_{1}, \gamma_{2}\right)$ in the unit interval, with $\gamma_{1}<\gamma_{\max }<\gamma_{2}$. Because $\partial F(\gamma) / \partial \gamma$ represents the second-order condition of our initial maximization problem, the root $\gamma_{2}$ is the maximum and characterizes $\gamma^{*}$, proving the existence of an equilibrium. Note that the second-order condition for a maximum of the expected profit of the principal, $E\left[\pi_{p}\right]$, is satisfied for $\gamma^{*}=\gamma_{2}>\gamma_{\max }$, because the slope of $F$ is negative, i.e., $\partial F(\gamma) /\left.\partial \gamma\right|_{\gamma=\gamma^{*}}<0$. Therefore, if $k^{2}<k_{\max }$, then $k^{2}<k_{\text {SOC }}$ holds for $\gamma^{*}$. Since there is only one intersection of $F(\gamma)$ with the $x$-axis satisfying the second-order condition $F^{\prime}(\gamma)<0$, uniqueness follows from existence.

If $k^{2}=k_{\max }$, then the first-order condition $F(\gamma)=0$ has one solution in the unit interval with $\gamma=\gamma_{\max }=2 /(3(1+\tau))$. In addition, it holds $\partial F(\gamma) /\left.\partial \gamma\right|_{\gamma=\gamma_{\max }}=0$ and $\partial^{3} E\left[\pi_{p}\right] / \partial a^{3}<0$ since $\partial^{2} F(\gamma) /\left.\partial \gamma^{2}\right|_{\gamma=\gamma_{\max }}=-6 k^{2} /\left(\rho \gamma_{\max }^{4}(1-\tau)\right)<0$. Therefore, the expected profit of the principal, $E\left[\pi_{p}\right]$, has a saddle point (and not a maximum) at $\gamma_{\max }$.

If $k^{2}>k_{\max }$, then $F(\gamma)$ lies below the $x$-axis in the unit interval, and thus no $\gamma$ exists that satisfies the first-order condition $F(\gamma)=0$.

${ }^{14}$ Formally, $\gamma_{\max }<1 \Leftrightarrow k^{2}<(1 / 2) \rho(1-\tau)^{2}(1+\tau)$ and $k_{\max }<(1 / 2) \rho(1-\tau)^{2}(1+\tau)$. 
Therefore, the condition $k^{2}<k_{\max }$ is sufficient and necessary. The equilibrium values $\left(a^{*}, b^{*}, \delta^{*}\right)$ directly follow from (5) and (6).

Q.E.D.

\section{A.3 Proof of Proposition 1}

Part (i): First, we will show that a higher bonus tax induces the agent to reduce the effort $a^{*}$. To prove this claim, recall that $F(\gamma, \tau)=(1-\tau)-\gamma\left(1-\tau^{2}\right)-k^{2} /$ $\left(\rho \gamma^{2}(1-\tau)\right)=0$ represents the principal's first-order condition. With the implicitfunction theorem, we derive

$$
\frac{\partial \gamma^{*}}{\partial \tau}=-\frac{\partial F / \partial \tau}{\partial F / \partial \gamma}=-\frac{-1+2 \gamma \tau-k^{2} /\left[\rho \gamma^{2}(1-\tau)^{2}\right]}{-\left(1-\tau^{2}\right)+2 k^{2} /\left[\rho \gamma^{3}(1-\tau)\right]} .
$$

With $a^{*}=(1-\tau) \gamma^{*}$, we obtain

$$
\frac{\partial a^{*}}{\partial \tau}=(1-\tau) \frac{\partial \gamma^{*}}{\partial \tau}-\gamma^{*}=\frac{\gamma\left(k^{2}-\rho \gamma^{2}(1-\tau)^{2}[1+\gamma(1-\tau)]\right)}{-2 k^{2}+\rho \gamma^{3}(1-\tau)^{2}(1+\tau)}=: \frac{A}{B}
$$

As $k^{2}<k_{\mathrm{SOC}}=(1 / 2) \rho \gamma^{3}(1-\tau)^{2}(1+\tau)$ for $\gamma=\gamma^{*}$, it holds that $B>0$. Moreover,

$$
A<0 \Leftrightarrow k^{2}<k^{*} \equiv \rho \gamma^{2}(1-\tau)^{2}[1+\gamma(1-\tau)] .
$$

We further derive that

$$
k^{*}>k_{\mathrm{SOC}} \Leftrightarrow 2>\gamma(3 \tau-1) \Leftrightarrow \underbrace{\frac{2}{\gamma}+1}_{\in(3, \infty)}>\underbrace{3 \tau}_{\in(0,3)} .
$$

The last inequality is always fulfilled, and therefore we have shown that $\partial a^{*} / \partial \tau<0$.

According to Lemma 1 , a higher bonus rate increases effort and reduces risktaking. Because the agent always reduces effort $a^{*}$ through a higher bonus tax, it follows that he increases risk-taking $b^{*}$, i.e., $\partial b^{*} / \partial \tau>0$. This proves part (i) of the proposition.

Part (ii): To show that a higher bonus tax induces the principal to reduce the bonus rate, i.e., $\partial \gamma^{*} / \partial \tau<0$, we provide a proof by contradiction. Suppose that $\partial \gamma^{*} / \partial \tau \geq 0$. The principal's first-order condition is given by $\gamma^{*}=1-k^{2} /\left(\rho\left(a^{*}\right)^{2}\right)-$ $a^{*} \tau /(1-\tau)$. Using the condition $a^{*}=(1-\tau) \gamma^{*}$, we obtain

$$
\gamma^{*}=1-\underbrace{\frac{k^{2}}{\rho\left(a^{*}\right)^{2}}}_{\text {inc. in } \tau}-\underbrace{\gamma^{*} \tau}_{\text {inc. in } \tau}
$$

Because $\partial a^{*} / \partial \tau<0$, the term $k^{2} /\left(\rho\left(a^{*}\right)^{2}\right)$ increases in $\tau$. Under the assumption that $\partial \gamma^{*} / \partial \tau \geq 0$, the term $\gamma^{*} \tau$ increases in $\tau$ as well. Hence, the right-hand side of (A2) decreases in $\tau$. It follows that the left-hand side of (A2) must decrease as 
well in equilibrium. This result, however, contradicts the assumption $\partial \gamma^{*} / \partial \tau \geq 0$. Hence, our assumption was wrong and it must be the case that $\partial \gamma^{*} / \partial \tau<0$.

To show that a higher bonus tax induces the principal to increase the fixed salary, i.e., $\partial \delta^{*} / \partial \tau>0$, recall that the fixed salary is given by

$$
\delta^{*}=\omega-\frac{1}{2}(1-\tau)^{2}\left(\gamma^{*}\right)^{2}-\frac{k^{2}}{2 \rho}=\omega-\frac{1}{2}\left(a^{*}\right)^{2}-\frac{k^{2}}{2 \rho} .
$$

Because $\partial a^{*} / \partial \tau<0$, the right-hand side of (A3) increases in $\tau$ and hence the lefthand side must increase as well, i.e., $\partial \delta^{*} / \partial \tau>0$. This proves part (ii) of the proposition.

\section{A.4 Proof of Proposition 2}

Recall that $\left(a^{*}, b^{*}\right)$ is given by $(5)$ and $\left(\gamma^{*}, \delta^{*}\right)$ is given by $(6)$.

Part (i): Total differentiation of $\gamma^{*}$ with $d \tau=0$ and $d k=0$ yields

$$
d \gamma=\frac{k^{2}}{\rho^{2}\left(a^{*}\right)^{2}} d \rho+\frac{2 k^{2}}{\rho\left(a^{*}\right)^{3}} d a-\frac{\tau}{1-\tau} d a .
$$

Total differentiation of $a^{*}$ with $d \tau=0$ produces $d a=(1-\tau) d \gamma$. Combining the two differentials, we obtain

$$
\begin{aligned}
& d \gamma=\frac{k^{2}}{\rho^{2}\left(a^{*}\right)^{2}} d \rho+\left(\frac{2 k^{2}}{\rho\left(a^{*}\right)^{3}}-\frac{\tau}{1-\tau}\right)(1-\tau) d \gamma \\
& \Leftrightarrow \frac{d \gamma}{d \rho}=\frac{k^{2} a^{*}}{(1+\tau) \rho^{2}\left(a^{*}\right)^{3}-2 \rho k^{2}(1-\tau)} .
\end{aligned}
$$

It is obvious that the numerator is positive in the last equation. At first sight, it seems that the denominator is ambiguous. However, a closer look at the denominator shows that it is unambiguously positive because

$$
\frac{d \gamma}{d \rho}>0 \Leftrightarrow(1+\tau) \rho^{2}\left(a^{*}\right)^{3}-2 \rho k^{2}(1-\tau)>0 \Leftrightarrow \frac{1}{2} \rho \gamma^{3}(1-\tau)^{2}(1+\tau)>k^{2} .
$$

The last inequality always holds because the second-order condition $k^{2}<k_{\mathrm{SOC}} \equiv$ $(1 / 2) \rho \gamma^{3}(1-\tau)^{2}(1+\tau)$ holds for $\gamma=\gamma^{*}$. The risk parameter has therefore a positive effect on the bonus rate. It is easy to see that the risk parameter also has a positive effect on effort, because $a^{*}=(1-\tau) \gamma^{*}$, so that

$$
\frac{d a}{d \rho}=(1-\tau) \underbrace{\frac{d \gamma^{*}}{d \rho}}_{>0}>0 .
$$


Next, we derive the effect of the risk parameter on $b^{*}=k /\left(\rho(1-\tau) \gamma^{*}\right)$. Total differentiation of $b^{*}$ with $d \tau=0$ and $d k=0$ yields

$$
d b=-\frac{k}{\rho^{2}(1-\tau) \gamma^{*}} d \rho-\frac{k}{\rho(1-\tau) \gamma^{2}} d \gamma .
$$

We substitute the above-calculated differential $d \gamma=\left[k^{2} a^{*} /\left((1+\tau) \rho^{2}\left(a^{*}\right)^{3}-\right.\right.$ $\left.\left.2 \rho k^{2}(1-\tau)\right)\right] d \rho$ into (A4), and after rearranging, we obtain

$$
\frac{d b}{d \rho}=-\frac{k}{\rho^{2}(1-\tau) \gamma^{*}}-\frac{k}{\rho(1-\tau) \gamma^{2}} \underbrace{\frac{k^{2} a^{*}}{(1+\tau) \rho^{2}\left(a^{*}\right)^{3}-2 \rho k^{2}(1-\tau)}}_{>0}<0 .
$$

This proves the claim that the risk parameter has a negative effect on risk-taking.

Part (ii): Total differentiation of $\gamma^{*}$ with $d \tau=0$ and $d \rho=0$ yields $d \gamma=$ $\left[-2 k /\left(\rho\left(a^{*}\right)^{2}\right)\right] d k+\left[2 k^{2} / \rho\left(a^{*}\right)^{3}\right] d a-[\tau /(1-\tau)] d a$. Total differentiation of $a^{*}$ with $d \tau=0$ produces $d a=(1-\tau) d \gamma$. Combining the two differentials, we obtain

$$
\begin{aligned}
& d \gamma=-\frac{2 k}{\rho\left(a^{*}\right)^{2}} d k+\left(\frac{2 k^{2}}{\rho\left(a^{*}\right)^{3}}-\frac{\tau}{1-\tau}\right)(1-\tau) d \gamma \\
& \Leftrightarrow \frac{d \gamma}{d k}=\frac{-2 k a^{*}}{(1+\tau) \rho\left(a^{*}\right)^{3}-2(1-\tau) k^{2}} .
\end{aligned}
$$

We derive that the bonus rate depends negatively on the project return parameter because

$$
\frac{d \gamma}{d k}<0 \Leftrightarrow(1+\tau) \rho\left(a^{*}\right)^{3}-2(1-\tau) k^{2}>0 \Leftrightarrow \frac{1}{2} \rho \gamma^{3}(1-\tau)^{2}(1+\tau)>k^{2} .
$$

The last inequality always holds because the second-order condition $k^{2}<k_{\mathrm{SOC}} \equiv$ $(1 / 2) \rho \gamma^{3}(1-\tau)^{2}(1+\tau)$ holds for $\gamma=\gamma^{*}$. Therefore, a higher return of the project, $k$, implies a lower bonus rate. Moreover, a higher $k$ has also a negative effect on effort $a^{*}=(1-\tau) \gamma^{*}$, because

$$
\frac{d a}{d \rho}=(1-\tau) \underbrace{\frac{d \gamma^{*}}{d k}}_{<0}<0 .
$$

Next, we derive the effect of the project return parameter $k$ on risk-taking $b^{*}=$ $k /\left(\rho(1-\tau) \gamma^{*}\right)$. We derive

$$
d b=\frac{1}{\rho(1-\tau) \gamma^{*}} d k-\frac{k}{\rho(1-\tau) \gamma^{2}} d \gamma
$$

and substitute the above-calculated differential $d \gamma=\left[-2 k a^{*} /\left((1+\tau) \rho\left(a^{*}\right)^{3}-\right.\right.$ $\left.\left.2(1-\tau) k^{2}\right)\right] d k$ into (A5). After rearranging, we obtain

$$
\frac{d b}{d k}=\frac{1}{\rho(1-\tau) \gamma^{*}}+\frac{1}{\rho(1-\tau) \gamma^{2}} \underbrace{\frac{2 k^{2} a^{*}}{(1+\tau) \rho\left(a^{*}\right)^{3}-2(1-\tau) k^{2}}}_{>0}>0 .
$$


This proves the claim that a higher project return parameter increases risk-taking.

Q.E.D.

\section{References}

Agranov, M., and C. Tergiman (2013), "Incentives and Compensation Schemes: An Experimental Study," International Journal of Industrial Organization, 31(3), 238-247.

Baker, G. (2002), "Distortion and Risk in Optimal Incentive Contracts," The Journal of Human Resources (JHR), 37(4), 728-751.

Bebchuk, L. A., and H. Spamann (2010), "Regulating Bankers' Pay," The Georgetown Law Journal, 98(2), 247-287.

Buehler, S., C. Kaiser, and F. Jaeger (2012), "The Geographic Determinants of Bankruptcy: Evidence from Switzerland," Small Business Economics, 39(1), 231-251.

Bustamante, M. C. (2014), "Strategic Investment and Industry Risk Dynamics," The Review of Financial Studies, Online First September 21, DOI: 10.1093/rfs/hhu067.

Carmel, J. (2008), "But Is it Myopia? Risk Aversion and the Efficiency of Stock-Based Managerial Incentives," Journal of Economics \& Management Strategy, 17(2), 541-579.

Chen, C. R., T. L. Steiner, and A. M. Whyte (2006), "Does Stock Option-Based Executive Compensation Induce Risk-Taking? An Analysis of the Banking Industry," Journal of Banking \& Finance, 30(3), 915-945.

Conyon, M. J., and G. V. Sadler (2001), "Executive Pay, Tournaments and Corporate Performance in UK Firms," International Journal of Management Reviews (IJMR), 3(2), $141-168$.

Core, J. E., W. R. Guay, and D. F. Larcker (2003), "Executive Equity Compensation and Incentives: A Survey," FRBNY Economic Policy Review, 9(1), 27-50.

Devers, C. E., A. A. Cannella, Jr., G. P. Reilly, and M. E. Yoder (2007), "Executive Compensation: A Multidisciplinary Review of Recent Developments," Journal of Management, 33(6), 1016-1072.

Dew-Becker, I. (2009), "How Much Sunlight does it Take to Disinfect a Boardroom? A Short History of Executive Compensation Regulation in America," CESifo Economic Studies, 55(3-4), 434-457.

Dietl, H. M., M. Grossmann, M. Lang, and S. Wey (2013), "Incentive Effects of Bonus Taxes in a Principal-Agent Model," Journal of Economic Behavior \& Organization, 89, 93-104.

Eichner, T., and M. Runkel (2011), "Corporate Income Taxation of Multinationals in a General Equilibrium Model," Journal of Public Economics, 95(7-8), 723-733.

Fama, E. F. (1980), "Agency Problems and the Theory of the Firm," Journal of Political Economy, 88(2), 288-307.

Faulkender, M., D. Kadyrzhanova, N. Prabhala, and L. Senbet (2010), "Executive Compensation: An Overview of Research on Corporate Practices and Proposed Reforms," Journal of Applied Corporate Finance, 22(1), 107-118.

Feltham, G. A., and J. Xie (1994), "Performance Measure Congruity and Diversity in MultiTask Principal/Agent Relations," The Accounting Review, 69(3), 429-453.

Garvey, G. T., S. Grant, and S. P. King (1999), "Myopic Corporate Behaviour with Optimal Management Incentives," The Journal of Industrial Economics, 47(2), 231-250.

Gibbons, R. (1998), "Incentives in Organizations," The Journal of Economic Perspectives, 12(4), 115-132.

Gomez-Mejia, L. R., J. E. McCann, and R. C. Page (1985), "The Structure of Managerial Behaviors and Rewards," Industrial Relations: A Journal of Economy and Society, 24(1), $147-154$.

Grossman, S. J., and O. D. Hart (1983), "An Analysis of the Principal-Agent Problem," Econometrica, 51(1), 7-45. 
Hall, B. J., and J. B. Liebman (2000), “The Taxation of Executive Compensation,” Tax Policy and the Economy, 14, 1-44.

Hellwig, M. F., and K. M. Schmidt (2002), "Discrete-Time Approximations of the Holmström-Milgrom Brownian-Motion Model of Intertemporal Incentive Provision," Econometrica, 70(6), 2225-2264.

Hirshleifer, D., and Y. Suh (1992), "Risk, Managerial Effort, and Project Choice," Journal of Financial Intermediation, 2(3), 308-345.

Holmström, B. (1979), "Moral Hazard and Observability," The Bell Journal of Economics, 10(1), 74-91.

Holmstrom, B. (1982), "Moral Hazard in Teams," The Bell Journal of Economics, 13(2), 324-340.

- and P. Milgrom (1987), "Aggregation and Linearity in the Provision of Intertemporal Incentives," Econometrica, 55(2), 303-328.

Hughes, J. S., L. Zhang, and J.-Z. J. Xie (2005), "Production Externalities, Congruity of Aggregate Signals, and Optimal Task Assignments," Contemporary Accounting Research, 22(2), 393-408.

Jensen, M. C., and W. H. Meckling (1976), "Theory of the Firm: Managerial Behavior, Agency Costs and Ownership Structure," Journal of Financial Economics, 3(4), 305-360.

— and K. J. Murphy (1990), "Performance Pay and Top-Management Incentives," Journal of Political Economy, 98(2), 225-264.

Knutt, N. (2005), "Executive Compensation Regulation: Corporate America, Heal thyself," Arizona Law Review, 47(2), 493-517.

Laux, C. A., and V. Laux (2006), "Performance Measurement and Information Production," Journal of Institutional and Theoretical Economics (JITE), 162(3), 412-423.

Lazear, E. P., and S. Rosen (1981), "Rank-Order Tournaments as Optimum Labor Contracts," Journal of Political Economy, 89(5), 841-864.

Marino, A. M., and J. Zábojník (2008), "Work-Related Perks, Agency Problems, and Optimal Incentive Contracts," The RAND Journal of Economics, 39(2), 565-585.

Mirrlees, J. A. (1976), "The Optimal Structure of Incentives and Authority within an Organization," The Bell Journal of Economics, 7(1), 105-131.

Murphy, K. J. (1999), "Executive Compensation," in: O. C. Ashenfelter and D. Card (eds.), Handbook of Labor Economics, Vol. 3B, North-Holland, Amsterdam, pp. 2485-2563.

Roider, A. (2009), "Delegation, Risk, and Project Scope," Journal of Institutional and Theoretical Economics (JITE), 165(2), 193-209.

Schaefer, S. (1998), "The Dependence of Pay-Performance Sensitivity on the Size of the Firm," The Review of Economics and Statistics, 80(3), 436-443.

Schöttner, A., and V. Thiele (2010), "Promotion Tournaments and Individual Performance Pay," Journal of Economics \& Management Strategy, 19(3), 699-731.

Sherstyuk, K. (2000), "Performance Standards and Incentive Pay in Agency Contracts," The Scandinavian Journal of Economics, 102(4), 725-736.

Thanassoulis, J. (2009), “This Is the Right Time to Regulate Bankers' Pay,” The Economists' Voice, 6(5), Article 2.

Wernerfelt, B. A. (2004), "Robust Incentive Contracts," Journal of Institutional and Theoretical Economics (JITE), 160(4), 545-554. 
Martin Grossmann

Department of Business

Administration

University of Zurich

Plattenstrasse 14

8032 Zurich

Switzerland

martin.grossmann@business.uzh.ch

Helmut Dietl

Department of Business

Administration

University of Zurich

Plattenstrasse 14

8032 Zurich

Switzerland

helmut.dietl@business.uzh.ch
Markus Lang

Department of Business

Administration

University of Zurich

Plattenstrasse 14

8032 Zurich

Switzerland

markus.lang@business.uzh.ch 